\title{
Core Professionalism Education in Surgery: A Systematic Review
}

\author{
Akile Sarığlu Büke1, Özlem Sürel Karabilgin Öztürkçü2, Yusuf Y1lmaz², İskender Sayek³ \\ ${ }^{1}$ Emeritus Professor of Paediatric Surgery, Pamukkale University School of Medicine, Denizli, Turkey \\ ${ }^{2}$ Department of Medical Education, Ege University School of Medicine, İzmir, Turkey \\ ${ }^{3}$ Emeritus Professor of Surgery, Hacettepe University School of Medicine, Ankara, Turkey
}

Background: Professionalism education is one of the major elements of surgical residency education.

Aims: To evaluate the studies on core professionalism education programs in surgical professionalism education.

Study Design: Systematic review.

Methods: This systematic literature review was performed to analyze core professionalism programs for surgical residency education published in English with at least three of the following features: program developmental model/instructional design method, aims and competencies, methods of teaching, methods of assessment, and program evaluation model or method. A total of 27083 articles were retrieved using EBSCOHOST, PubMed, Science Direct, Web of Science, and manual search.

Results: Eight articles met the selection criteria. The instructional design method was presented in only one article, which described the Analysis, Design, Development, Implementation, and Evaluation model. Six articles were based on the Accreditation Council for Graduate Medical Education criterion, although there was significant variability in content. The most common teaching method was role modeling with scenario- and case-based learning. A wide range of assessment methods for evaluating professionalism education were reported. The Kirkpatrick model was reported in one article as a method for program evaluation.

Conclusion: It is suggested that for a core surgical professionalism education program, developmental/instructional design model, aims and competencies, content, teaching methods, assessment methods, and program evaluation methods/models should be well defined, and the content should be comparable.

Keywords: Education, residency, medical, surgical professionalism, systematic review
Professionalism is briefly defined as a "social contract" with the society, and is a crucial element of medical practice along with the healing role (1). One of the driving forces for defining professionalism in medicine and surgery was a response to the rapid expansion of the concept of commercialism and associated ethics in these professions. Defining professionalism for medical specialties remains somewhat controversial, but it has been proposed that the main professional values include altruism, respect, honesty, integrity, dutifulness, honor, excellence, and accountability $(1,2)$. The definition of professionalism in medicine has been developed by the American Board of Internal Medicine Foundation, American College of Physicians Foundation, and European Federation of Internal Medicine and published as "Medical Professionalism in the New Millennium: A Physician Charter". Various countries, professional associations, and councils have studied and accepted this code of professionalism (3-8). In addition, university project groups have been established, and conferences have been held on topics, such as the concept of professionalism and its implications in surgical practice and implementation of professionalism education in the field of surgery (9-12). However, despite all the studies on professionalism, defining it remains challenging. Although professionalism education is one of the major concerns in medical and surgical training programs worldwide, the implementation and assessment of these programs remain debatable (13-16). It has been suggested that professionalism education includes character development, and implementation of a professionalism education program has been described as designing to educe latent wisdom" $(17,18)$. Parker et al. (19) proposed an orientation program and commitment to professionalism in their Pyramid of Professionalism education model which was tailored for medical students. To initiate an individual's commitment to professionalism, we defined for the Core Professionalism Education Program (COPEP), which is a start-up program for the development of an individual's professional values. A comprehensive surgical education

Address for Correspondence: Dr. Özlem Sürel Karabilgin Öztürkçü, Department of Medical Education, Ege University Schol of Medicine, İzmir, Turkey

e-mail: o.surel.karabilgin@ege.edu.trＯORCID ID: orcid.org/0000-0002-3271-0432

Received: 18 May 2017 Accepted: 7 December 2017 • DOI: 10.4274/balkanmedj.2017.0534

Available at www.balkanmedicaljournal.org

Cite this article as:

Sarığlu Büke A, Karabilgin Öztürkçü ÖS, Yılmaz Y, Sayek İ. Core Professionalism Education in Surgery: A Systematic Review. Balkan Med J 2018;35:167-73

${ }^{\circ}$ Copyright 2018 by Trakya University Faculty of Medicine / The Balkan Medical Journal published by Galenos Publishing House. 
program should start with COPEP and integrate professionalism throughout the educational period. COPEP can be planned for surgical residents as well as medical students. The aim of this systematic review was to evaluate studies on COPEP in surgery (COPEPS) for surgical residents.

\section{MATERIALS AND METHODS}

We searched for articles on COPEPS that described a professionalism program conducted during surgical training, including program development model/instructional design methods, aims and competencies, methods of teaching, methods of assessment, and program evaluation model $/$ method. COPEPSs that targeted surgical residents and possessed at least three of the abovementioned characteristics were included.

\section{Review group}

The study review group comprised four members: an emeritus member of the academic staff in Pediatric Surgery who was also a philosophiae doctor student in Medical Education, member of the academic staff in Medical Education, instructional designer in Medical Education, and emeritus member of the academic staff in Surgery who was the chair of the Association for the Evaluation and Accreditation of Medical Education Programs in Turkey.

\section{Search strategy}

A detailed search was conducted between February 2015 and April 2015, and articles published between January 2005 and January 2015 were included. The start date was chosen as 1 year after the Surgical Task Force on Professionalism began in 2003. The Medical Subject Headings (MeSH) words and search strings used are presented in Table 1. Electronic databases searched included EBSCOHOST, PubMed, Science Direct, and Web of Science. The word "professionalism" was not present in the PubMed MeSH vocabulary; hence, a suggestion was made to National Institutes of Health for its inclusion. The research material was collected in Mendeley under separate folders according to the databases searched and time of search. We also searched the web for gray literature, such as proceedings and congress papers. In addition, a separate manual search of the Journal of Surgical Education, Medical Teacher, Medical Education, Academic Medicine, and Clinical Teacher was conducted. References from 11 outstanding articles and reviews were also manually searched (20).

\section{Selection of eligible articles}

The articles were reviewed to select the eligible ones. Articles including at least three components of COPEPS (program developmental model/instructional design method, aims and competencies, methods of teaching, methods of assessment, or program evaluation model/method) were included. Furthermore, both qualitative and quantitative reports were included. Articles that described COPEPSs associated with core surgical professionalism education programs for residents and for others were also included. Articles published in languages other than English and those related to only nonsurgical residency, undergraduate medical education, and continuing medical education programs were excluded. Articles based on programs that claimed of teaching professionalism as a component of other competencies and/or teaching other competencies, such as technical skills (i.e., integrated programs) (21-38); those based on programs that taught only one component of professionalism, such as leadership (39-41); and those based on programs with only one component of program development or instructional design, such as assessment $(22,23,42-48)$ were also excluded. Data were extracted and collated into an Excel program by the first reviewer. The articles were then rechecked by the first reviewer. Next, the selected articles were separately reviewed by two reviewers to screen eligible articles. Intra- and inter-rater agreements were calculated.

\section{RESULTS}

A total of 27.083 articles were retrieved from EBSCOHOST, PubMed, Science Direct, Web of Science, and manual search (Table 2). A flow diagram of the systematic review is presented in Figure 1. After eliminating duplicates and screening the articles by titles, the remaining 930 articles were screened for those based on professionalism and surgery. As a result, 342 articles were selected. Then, these articles were reviewed for the exclusion criteria. The first reviewer analyzed 342

TABLE 1. MeSH words and search strings used in the literature search

MeSH/search string
\#1. Professionalism and surgeon and education
\#2. Professionalism and surgical education
\#3. Professionalism and surgical resident
\#4. Professionalism education and surgery
\#5. Professionalism education and surgical education
\#6. Professionalism education and surgical resident
\#7. Surgical professionalism and education
\#8. Medical professionalism and surgery
\#9. \#8 and education
\#10. Professionalism and surgery
$\# 11 . \# 10$ and vocational training
\#12. \#10 and specialty training
$\# 13 . \# 10$ and resident
MeSH: Medical subject headings


articles twice in the given time range and identified 16 artciles that reported on COPEPS. Intra-rater agreement for the first reviewer was $97.07 \%$ (Cohen's kappa $=0.532$ ). The 16 articles selected were reviewed again by the two reviewers to select the articles containing at least three components of COPEPS. To ensure reliability throughout the research, intra- and interrater reliability measurements were evaluated. The inter-rater reliability results showed a high level of agreement between

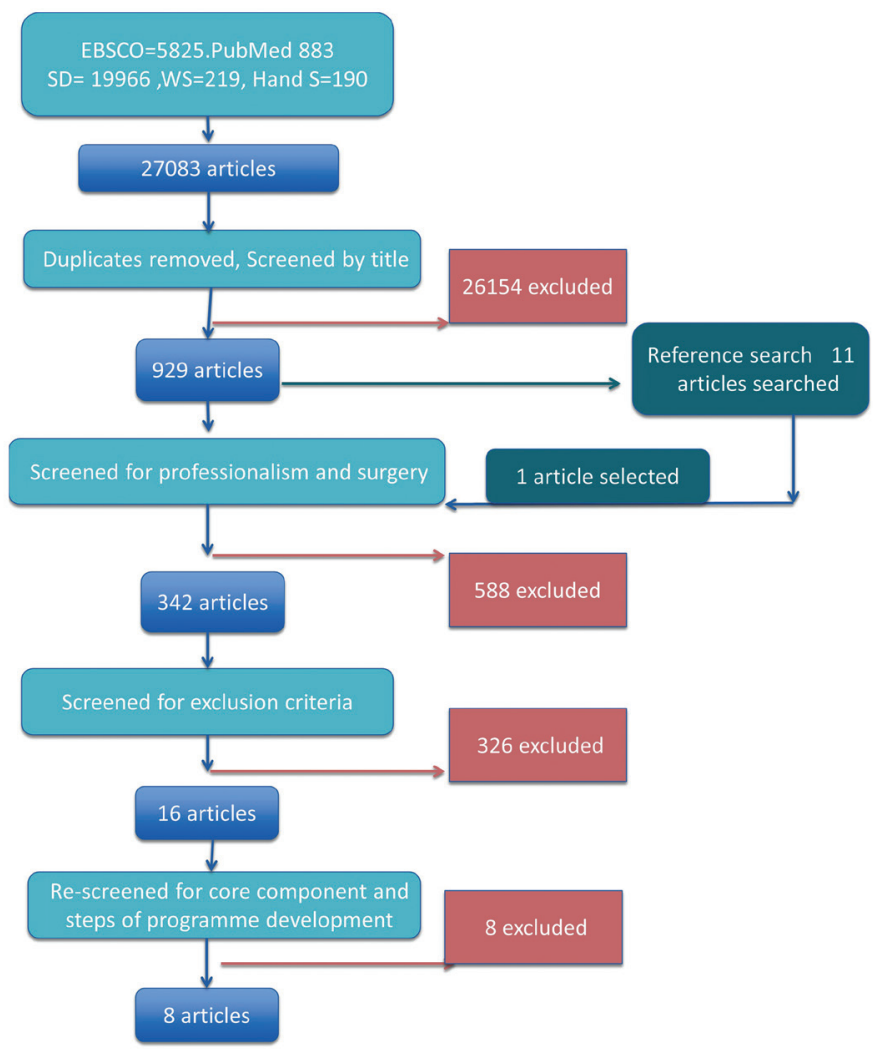

FIG. 1. Flowchart of the systematic review.

TABLE 2. The databases searched and search strategies employed

\begin{tabular}{lcc}
\hline Database & Search strategy & $\begin{array}{c}\text { Number of } \\
\text { articles }\end{array}$ \\
\hline EBSCOHOST & $\begin{array}{c}\text { Search in full article, word search } \\
\text { Date range: January 2005 to January } \\
2015\end{array}$ & 5.825 \\
PubMed & $\begin{array}{c}\text { Date range: January 2005 to January } \\
2015\end{array}$ & 883 \\
Science direct & $\begin{array}{c}\text { All sources, all sciences } \\
\text { Date range: January 2005 to January } \\
2015\end{array}$ & 19.966 \\
Web of science & $\begin{array}{c}\text { Search language, auto } \\
\text { Date range: January 2005 to January } \\
\text { 2015 }\end{array}$ & 219 \\
Manual search & $\begin{array}{c}\text { Journal of surgical education, medical } \\
\text { teacher, medical education, academic } \\
\text { medicine, and clinical teacher }\end{array}$ & 190 \\
Total & $\quad$ \\
\hline
\end{tabular}

the two reviewers $($ Cohen's kappa $=0.625)$, indicating that there was an acceptable agreement between the two reviewers for most articles $(49,50)$. Eight articles $(9,10,51-56)$ met the research criteria and were analyzed to delineate COPEPS. Three of these reported a component shared with COPEPs for other residents, faculty, nurses, and students. Details regarding the analysis of the eight articles are presented in Table 3.

\section{DISCUSSION}

We concluded that COPEPS is necessary to orient surgical residents toward the principles of surgical professionalism. The residents are expected to understand that professionalism is a social contract and in fact their social contract starts as soon as they start working as a professional. The implementation of this core program is therefore crucial. In this systematic review, we identified eight articles on COPEPS that met the review criteria. These selected articles covered programs specific to COPEPS during surgical residency. A combined core component targeting faculty, residents, nurses, and medical students was detected in addition to the core component for surgical residents (54-56). These combined programs could be useful to nurture teamwork, but the authors suggested that the core component for surgical residents should not be neglected. Only one article covered the instructional design method, describing the Analysis, Design, Development, Implementation, and Evaluation model (54). All the selected articles prescribed a method for COPEPS, although a particular method was not specified. Six articles specified the Accreditation Council for Graduate Medical Education (ACGME), whereas one specified the nine domains of Royal Australian College of Surgeons as COPEPS criteria. Because it is difficult to define professionalism, we suggest that the baseline criteria should be used as a guide for developing COPEPS. Even when the aims and competencies of COPEPS were based on those specified by ACGME, a wide range of differences were observed in their content, except two consecutive articles describing the same program. We suggest that it is better to develop COPEPS on the basis of criteria that are universal or associated with a national professional association or content that completely defines professionalism, and should be comparable. The duration of the implemented programs described in the articles varied from hours to a year. Hochberg et al. (53) preferred to provide core professionalism education throughout the year, including surgical residents in their first, second, and third years of training simultaneously $(9,53)$. Another important point is to provide COPEPS at the beginning of surgical residency. In the following years, COPEPS could be supported by integrated surgical professionalism education or refresher programs. We believe that for COPEPS, both conditions can be 


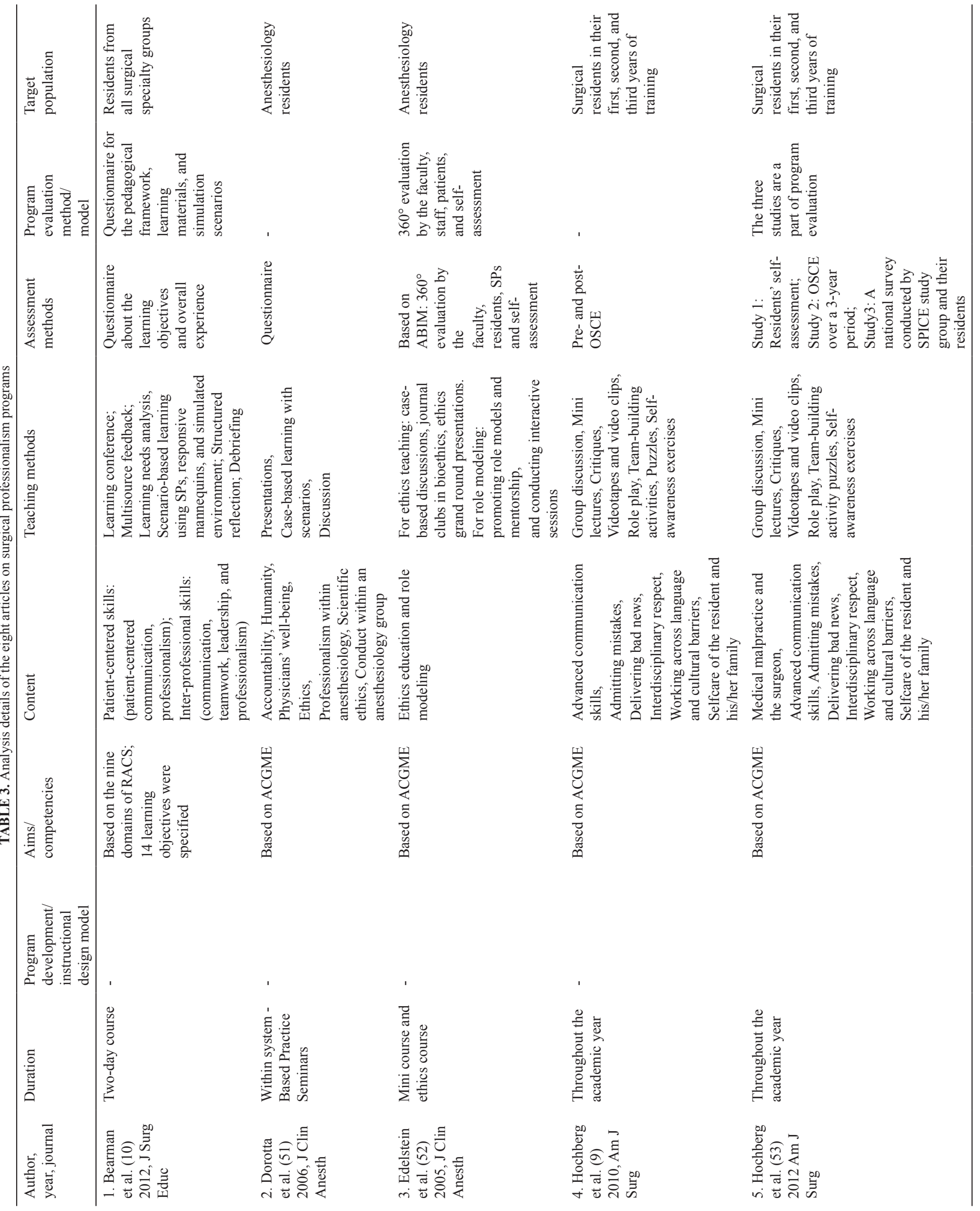




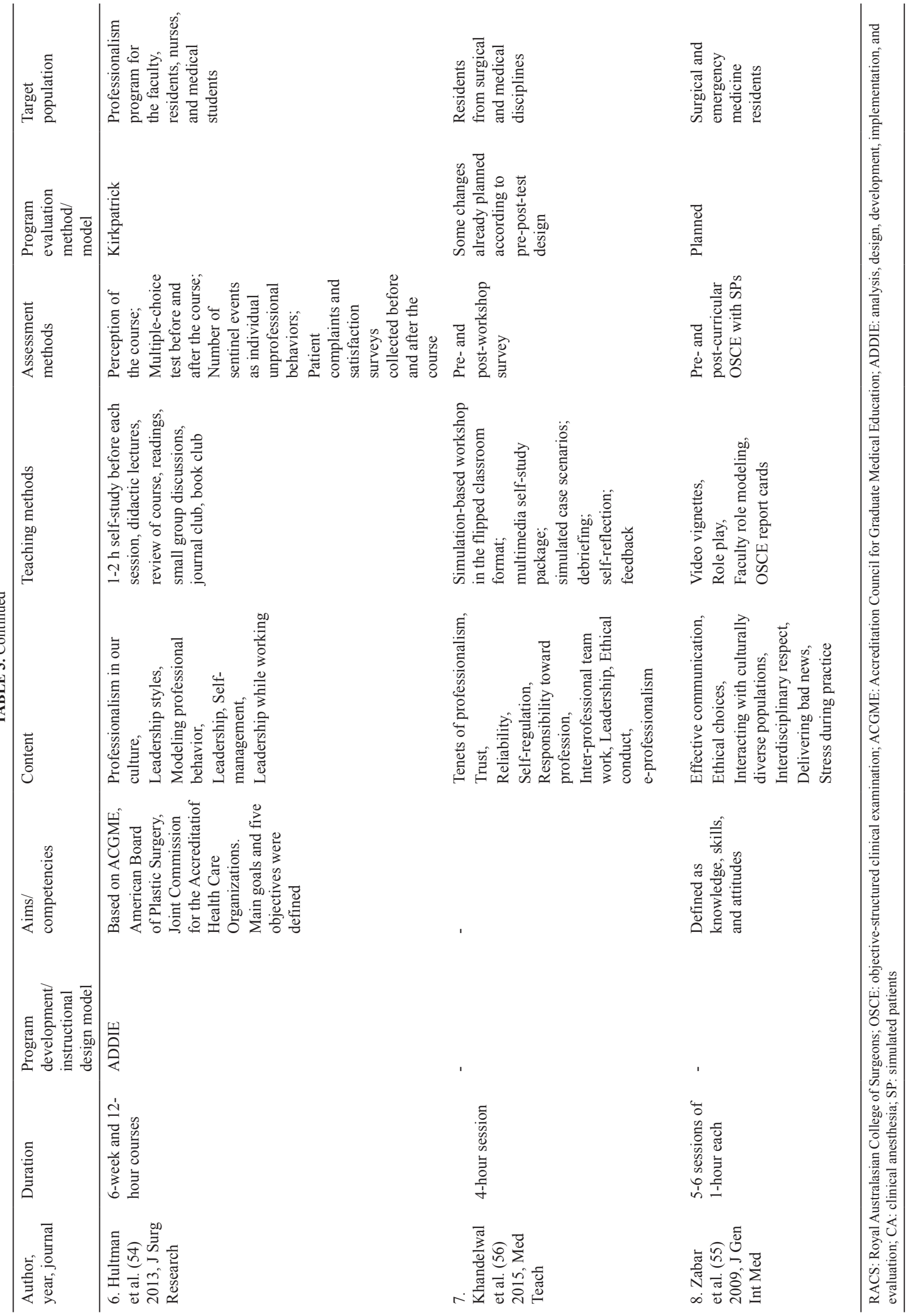


applied, depending on the requirements of surgical residents, provided that the basic principles of professionalism education are followed. The most common teaching methods described were role modeling and scenario- and case-based learning. Other methods included conferences using multisource feedback and learning analysis, discussion, reflection, selfreflection, debriefing, mentorship, self-awareness exercises, team-building activities, role play, journal and book clubs, grand round presentations, and objective-structured clinical examination (OSCE). Other teaching methods included the use of simulated environments, simulated patients, mannequins, videotapes, and video clips. A recently published article also described the use of flipped classrooms. It has been reported that role modeling and mentoring were the most frequently used teaching methods for professionalism education $(57,58)$. The evaluation of professionalism is another important issue $(16,18,43,59)$. The methods of evaluation reported in the articles included $\mathrm{OSCE}, 360^{\circ}$ evaluation, self-assessment, national survey, patient complaint and satisfaction survey, standard patient questionnaires, and multiple-choice questions. However, if surgical residents are expected to develop professional behavior and attitude, it would not be appropriate to use only multiple-choice tests and questionnaires for evaluation. The evaluation of a professionalism education program is also extremely important. The Kirkpatrick model of program evaluation was used in one of the selected articles (60). Other reported methods included questionnaires, $360^{\circ}$ evaluation, and pre- and post-test designs.

The lack of consensus regarding professionalism education can be regarded as a limitation of this study (13).

Teaching professionalism needs a cognitive base, but environment is also important; hence, principles from both cognitive and situated learning theories should be applied (57). Some institutions have tried to achieve this by establishing an institutional culture or ecology of professionalism within the institution through professionalism improvement activities (6163). Surgical residents interact with other people as a part of a complex system, and education is imparted everywhere. Thus, a core or even an integrated professionalism education program would not be sufficient; it would be better to cultivate a culture of professionalism throughout the clinic and institution. We detected that a complete professionalism education program for surgical residents begin with COPEPS, and that COPEPS should end with a written commitment. Additionally, COPEPS should include the steps of instructional design and should be well defined and elaborately constructed in accordance with the regulations of national and international associations.

Financial Disclosure: The databases of Ege University were used and other financial resources have been obtained by the authors.
Conflict of Interest: No conflict of interest was declared by the authors.

\section{REFERENCES}

1. Cruess SR, Cruess RL, Steinert Y. Linking the teaching of professionalism to the social contract: a call for cultural humility. Med Teach 2010;32:357-9.

2. Cohen JJ. Professionalism in medical education, an American perspective: from evidence to accountability. Med Educ 2006;40:607-17.

3. Cogbill TH, Malangoni MA, Potts JR, Valentine RJ. The General Surgery Milestones Project. J Am Coll Surg 2014;218:1056-62.

4. Cooney CM, Redett RJ, Dorafshar AH, Zarrabi B, Lifchez SD. Integrating the NAS Milestones and handheld technology to improve residency training and assessment. J Surg Educ 2014;71:39-42.

5. Lee AG, Arnold AC. The ACGME Milestone Project in Ophthalmology. Surv Ophthalmol 2013;58:359-69.

6. White CP, Lecours C, Bortoluzzi P, Caouette-Laberge L, Ying Y. International plastic surgery missions: a framework for resident education using the CanMEDS competencies. Ann Plast Surg 2013;71:324-7.

7. Cote L, Laughrea PA. Preceptors' understanding and use of role modeling to develop the CanMEDS competencies in residents. Acad Med 2014;89:934-9.

8. Bradburn M, Staley H. Professionalism. Dev Leadersh Surg Train 2012;30:499-502.

9. Hochberg MS, Kalet A, Zabar S, Kachur E, Gillespie C, Berman RS. Can professionalism be taught? Encouraging evidence. Am J Surg 2010;199:86-93.

10. Bearman M, O'Brien R, Anthony A, Civil I, Flanagan B, Jolly B, et al. Learning Surgical Communication, Leadership and Teamwork Through Simulation. J Surg Educ 2012;69:201-7.

11. Schulz K, Puscas L, Tucci D, Woodard C, Witsell D, Esclamado RM, et al. Surgical Training and Education in Promoting Professionalism: a comparative assessment of virtue-based leadership development in otolaryngology-head and neck surgery residents. Med Educ Online 2013;18:22440.

12. Doukas DJ, Kirch DG, Brigham TP, Barzansky BM, Wear S, Carrese JA, Fins JJ, et al. Transforming Educational Accountability in Medical Ethics and Humanities Education Toward Professionalism. Acad Med 2015;90:738-43.

13. Birden H, Glass N, Wilson I, Harrison M, Usherwood T, Nass D. Defining professionalism in medical education: a systematic review. Med Teach 2014;36:47-61.

14. Al-Eraky MM. Twelve Tips for teaching medical professionalism at all levels of medical education. Med Teach 2015;37:1018-25.

15. Deptula P, Chun MB. A literature review of professionalism in surgical education: suggested components for development of a curriculum. J Surg Educ 2013;70:40822 .

16. Elcin M, Odabasi O, Gokler B, Sayek I, Akova M, Kiper N. Developing and evaluating professionalism. Med Teach 2006;28:36-9.

17. Cruess RL, Cruess SR, Yvonne S. Teaching Medical Professionalism. Cambridge University Press: Cambridge, UK; 2009.

18. Hodges BD, Ginsburg S, Cruess R, Cruess S, Delport R, Hafferty F, et al. Assessment of professionalism: recommendations from the Ottawa 2010 Conference. Med Teach 2011;33:354-63.

19. Parker M, Luke H, Zhang J, Wilkinson D, Peterson R, Ozolins I. The "pyramid of professionalism": seven years of experience with an integrated program of teaching, developing, and assessing professionalism among medical students. Acad Med 2008;83:733-41.

20. Haig A, Dozier M. BEME guide no. 3: systematic searching for evidence in medical education part 2: constructing searches. Med Teach 2003;25:463-84.

21. Antonoff MB, D'Cunha J. PGY-1 Surgery Preparatory Course Design: Identification of Key Curricular Components. J Surg Educ 2011;68:478-84.

22. Davis D, Lee G. The use of standardized patients in the plastic surgery residency curriculum: teaching core competencies with objective structured clinical examinations. Plast Reconstr Surg 2011;128:291-8.

23. Fontes RB, Selden NR, Byrne RW. Fostering and assessing professionalism and communication skills in neurosurgical education. J Surg Educ 2014;71:83-9.

24. Gold JP, Begg WB, Fullerton DA, Mathisen DJ, Orringer MB, Verrier ED. Evaluation of Web-Based Learning Tools: Lessons Learned from the Thoracic Surgery Directors Association Curriculum Project Three-Year Experience. Ann Thorac Surg 2005;80:802-9. 
25. Greenberg JA, Irani JL, Greenberg CC, Blanco MA, Lipsitz S, Ashley SW. The ACGME competencies in the operating room. Surgery 2007;142:180-4.

26. Kauffmann RM, Landman MP, Shelton J, Dmochowski RR, Bledsoe SH, Hickson GB, et al. The Use of a Multidisciplinary Morbidity and Mortality Conference to Incorporate ACGME General Competencies. J Surg Educ 2011;68:303-8.

27. Kirton OC, Reilly P, Staff I, Burns K. Development and Implementation of an Interactive, Objective, and Simulation-Based Curriculum for General Surgery Residents. J Surg Educ 2012;69:718-23.

28. Larkin AC, Cahan MA, Whalen G, Hatem D, Starr S, Haley HL. Human Emotion and Response in Surgery (HEARS): A Simulation-Based Curriculum for Communication Skills, Systems-Based Practice, and Professionalism in Surgical Residency Training. J Am Coll Surg 2010;211:285-92.

29. Miller N, MacNew H, Nester J, Wiggins JB, Shealy C, Senkowski C. Jump starting a quality and performance improvement initiative to meet the updated ACGME guidelines. J Surg Educ 2013;70:758-68.

30. Mitchell EL, Arora S, Moneta GL. Ensuring vascular surgical training is on the right track. J Vasc Surg 2011;53:517-25.

31. Patterson BR, Kimball KJ, Walsh-Covarrubias JB, Kilgore LC. Effecting the sixth core competency: a project-based curriculum. Am J Obstet Gynecol 2008;199:561.

32. Pearson AS, McTigue MP, Tarpley JL. Narrative Medicine in Surgical Education. J Surg Educ 2008;65:99-100.

33. Ponton-Carss AC, Donnon T, Kortbeek JB. Two for one: surgical skills and CanMEDS roles a combined course for surgical residents. J Surg Educ 2014;71:419-25.

34. Rousseau A, Saucier D, Cote L. Introduction to core competencies in residency: a description of an intensive, integrated, multispecialty teaching program. Acad Med 2007;82:563-8.

35. Selden NR, Origitano TC, Burchiel KJ, Getch CC, Anderson VC, McCartney S, et al. A national fundamentals curriculum for neurosurgery PGY1 residents: the 2010 Society of Neurological Surgeons boot camp courses. Neurosurgery 2012;70:97181.

36. Skolarikos A, Gravas S, Laguna MP, Traxer O, Preminger GM, de la Rosette J. Training in ureteroscopy: a critical appraisal of the literature. BJU Int 2011;108:798805.

37. Tso MO, Goldberg MF, Lee AG, Selvarajah S, Parrish RK, Zagorski Z. An International Strategic Plan to Preserve and Restore Vision: Four Curricula of Ophthalmic Education. Am J Ophthalmol 2007;143:859-65.

38. Wang TT, Ahmed K, Patel VM, Harling L, Jawad M, Darzi A, et al. A competency framework in cardiothoracic surgery for training and revalidation - an international comparison. Eur J Cardiothorac Surg 2011;40:816-25.

39. Hochberg MS, Seib CD, Berman RS, Kalet AL, Zabar SR, Pachter HL. Perspective: Malpractice in an academic medical center: a frequently overlooked aspect of professionalism education. Acad Med 2011;86:365-8.

40. Klingensmith ME. Teaching Ethics in Surgical Training Programs Using a CaseBased Format. J Surg Educ 2008;65:126-8.

41. Krajewski A, Rader C, Voytovich A, Longo WE, Kozol RA, Chandawarkar RY. Improving Surgical Residents' Performance on Written Assessments of Cultural Competency. J Surg Educ 2008;65:263-9.

42. Aramesh K, Mohebbi M, Jessri M, Sanagou M. Measuring professionalism in residency training programs in Iran. Med Teach 2009;31:356-61.

43. Cruess R, Mcllroy JH, Cruess S, Ginsburg S, Steinert Y. The professionalism mini-evaluation exercise: A preliminary investigation. Acad Med 2006;81(10 Suppl):74-8.

44. Dwyer T, Glover Takahashi S, Kennedy Hynes M, Herold J, Wasserstein D, Nousiainen M, et al. How to assess communication, professionalism, collaboration and the other intrinsic CanMEDS roles in orthopedic residents: use of an objective structured clinical examination (OSCE). Can J Surg 2014;57:230-6.
45. Falcone JL, Claxton RN, Marshall GT. Communication skills training in surgical residency: a needs assessment and metacognition analysis of a difficult conversation objective structured clinical examination. J Surg Educ 2014;71:309-15.

46. Zhao Y, Zhang X, Chang Q, Sun B. Psychometric Characteristics of the 360 degrees Feedback Scales in Professionalism and Interpersonal and Communication Skills Assessment of Surgery Residents in China. J Surg Educ 2013;70:628-35.

47. Tsugawa Y, Ohbu S, Cruess R, Cruess S, Okubo T, Takahashi O, et al. Introducing the Professionalism Mini-Evaluation Exercise (P-MEX) in Japan: results from a multicenter, cross-sectional study. Acad Med 2011;86:1026-31.

48. Qu B, Zhao YH, Sun BZ. Evaluation of residents' competency in professionalism and communication skills in northern China: a 360-degree assessment. Med Teach 2010;32:701-2.

49. Lombard M, Snyder-Duch J, Bracken CC. Content Analysis in Mass Communication: Assessment and Reporting of Intercoder Reliability. Hum Commun Res 2002;28:587-604.

50. Neuendorf KA. The content analysis guidebook. SAGE Publications, Thousand Oaks, CA; 2002.

51. Dorotta I, Staszak J, Takla A, Tetzlaff JE. Teaching and evaluating professionalism for anesthesiology residents. J Clin Anesth 2006;18:148-60.

52. Edelstein SB, Stevenson JM, Broad K. Teaching professionalism during anesthesiology training. J Clin Anesth 2005;17:392-8.

53. Hochberg MS, Berman RS, Kalet AL, Zabar SR, Gillespie C, Pachter HL, et al. The professionalism curriculum as a cultural change agent in surgical residency education. Am J Surg 2012;203:14-20.

54. Hultman CS, Halvorson EG, Kaye D, Helgans R, Meyers MO, Rowland PA, et al Sometimes you can't make it on your own: the impact of a professionalism curriculum on the attitudes, knowledge, and behaviors of an academic plastic surgery practice. $\mathrm{J}$ Surg Res 2013;180:8-14.

55. Zabar S, Regan LA, Hochberg M, et al. Targeted communication and professionalism GME curricula lead to practice improvement: the SPICE (Surgical Professionalism and Interpersonal Communicaiton Education) and EMPACT (Emergency Medicine Professionalism and Communicaiton Training) experience. J Gen Intern Med 2009;24:177.

56. Khandelwal A, Nugus P, Elkoushy MA, Cruess RL, Cruess SR, Smilovitch M. How we made professionalism relevant to twenty-first century residents. Med Teach 2015;37:538-42.

57. Cruess RL, Cruess SR. Teaching professionalism: general principles. Med Teach 2006;28:205-8.

58. Birden H, Glass N, Wilson I, Harrison M, Usherwood T, Nass D. Teaching professionalism in medical education: A Best Evidence Medical Education (BEME) systematic review. BEME Guide No. 25. Med Teach 2013;35:1252-6.

59. Tsugawa Y, Tokuda Y, Ohbu S, Okubo T, Cruess R, Cruess S, et al. Professionalism Mini-Evaluation Exercise for medical residents in Japan: a pilot study. Med Educ 2009;43:968-78.

60. Hultman CS, Halvorson EG, Kaye D, Helgans R, Meyers MO, Rowland PA, et al Sometimes you can't make it on your own: the impact of a professionalism curriculum on the attitudes, knowledge, and behaviors of an academic plastic surgery practice. $\mathrm{J}$ Surg Res 2013;180:8-14.

61. Fryer-Edwards K, Van Eaton E, Goldstein EA, Kimball HR, Veith RC, Pellegrini $\mathrm{CA}$, et al. Overcoming institutional challenges through continuous professionalism improvement: the University of Washington experience. Acad Med 2007;82:1073-8.

62. Goldstein EA, Maestas RR, Fryer-Edwards K, Wenrich MD, Oelschlager AM, Baernstein A, et al. Professionalism in medical education: an institutional challenge. Acad Med 2006;81:871-6.

63. Smith KL, Saavedra R, Raeke JL, O'Donell AA. The journey to creating a campuswide culture of professionalism. Acad Med 2007;82:1015-21. 